\title{
O TRABALHO DE CAMPO ETNOGRÁFICO EM INSTITUIÇÃO DE LONGA PERMANÊNCIA PARA IDOSOSa
}

The ethnographic fieldwork in a long-stay institution for the elderly

El trabajo de campo etnográfico en una institución de larga estancia para personas mayores

Maria Helena Lenardt ${ }^{2}$

\section{RESUMO}

0 estudo teve como objetivo relatar o desenvolvimento do trabalho de campo etnográfico em uma instituição de longa permanência para idosos. Trata-se de relato de experiência enfatizando os aspectos metodológicos desta vivência por meio de ferramentas originárias de estudos culturais antropológicos. Apresentam-se os caminhos metodológicos adotados ao longo do desenvolvimento da coleta, registro e análise das informações, utilizando a observação participante e entrevista etnográfica. Seguiu-se o padrão cíclico do método etnográfico proposto por Spradley e McCurdy, no qual os dados obtidos foram repetidamente confirmados e aprofundados por outras observações e entrevistas. As técnicas utilizadas mostraram-se valiosas para a revelação antropológica. As vivências no cotidiano da ILPI foram momentos ricos em aprendizado e investigação, percebendo a amplitude da influência que as dimensões culturais têm no cotidiano e comportamentos humanos. 0 desenvolvimento da habilidade do olhar antropológico entre os profissionais de Enfermagem pode aperfeiçoar as práticas de saúde.

Palavras-chave: Assistência de longa duração. Cultura. Pesquisa em Enfermagem

\begin{abstract}
The study aimed to report the development of ethnographic fieldwork in a long-stay institution for the elderly. It is an experience report emphasizing the methodological aspects of this experience using tools from cultural anthropological studies. Presents the methodology adopted during the development of collecting, recording and analysis of the information, using participant observation and ethnographic interviews. Followed the cyclical pattern of the ethnographic method proposed by Spradley and McCurdy, in which the data were repeatedly confirmed and extended by other observations and interviews. The techniques used seemed valuable for anthropological revelation. The experiences in everyday moments in institution were rich in learning and research, realizing the magnitude of the influence that cultural dimensions have on daily life, human behavior and nursing care. The development of antropological skills among nursing professionals can improve health practices.
\end{abstract}

Keywords: Long-Term Care. Culture. Nursing Research

\section{Resumen}

El estudio tuvo por objetivo relatar el desarrollo del trabajo de campo etnográfico en una institución de larga estancia para personas mayores. Se trata de un relato de experiencia enfatizando los aspectos metodológicos de esta experiencia en el uso de herramientas de los estudios culturales antropológicos. Presenta la metodología utilizada durante el desarrollo de la recolección, registro y análisis de la información, mediante la observación participante y entrevistas etnográficas. Siguió el patrón cíclico del método etnográfico propuesto por Spradley y McCurdy, en que los datos fueron varias veces confirmados e ampliados por otras observaciones y entrevistas. Las técnicas utilizadas se mostraron valiosas para la revelación antropológica. Las experiencias cotidianas de la institución fueron momentos ricos en aprendizaje e investigación, dándose cuenta de la magnitud de la influencia de las dimensiones culturales en la vida cotidiana, comportamiento humano y cuidados de enfermería. El desarrollo de habilidades de la antropología entre los profesionales de enfermería pueden mejorar las prácticas de salud.

Palabras clave: Cuidados a Largo Plazo. Cultura. Investigación en enfermería

\footnotetext{
${ }^{1}$ Enfermeira. Doutoranda do Programa de Pós-Graduação em Enfermagem da UFPR. Bolsista REUNI/UFPR. Membro do GMPI. Curitiba-PR. Brasil. Email: tatiane.michel@uol.com.br;' Enfermeira. Doutora em Filosofia da Enfermagem. Professora Sênior do Programa de Pós-Graduação em Enfermagem da Universidade Federal do Paraná (UFPR). Líder do Grupo Multiprofissional de Pesquisa sobre Idosos (GMPI/UFPR). Curitiba-PR. Brasil. Email: curitiba.helena@gmail.com
} 


\section{INTRODUÇÃO}

As pessoas utilizam constantemente um complexo sistema de significados - o qual constitui sua cultura - para organizar o seu comportamento e compreender o mundo em que vivem ${ }^{1}$. 0 significado pode ser entendido sob a ótica de diferentes áreas do conhecimento, e suas distintas abordagens conduzem à utilização de fundamentação teórica de acordo com os caminhos metodológicos e os resultados a serem obtidos.

A antropologia interpretativa desenvolve técnicas que nos levam a ver como o outro vê e assim entender outra cultura a partir da análise das formas simbólicas em cujos termos as pessoas representam para si mesmas e para os outros. Na busca da compreensão das concepç̃̃es do outro, as nossas próprias concepções são colocadas de lado para observar os fenômenos na visão dos atores².

0 trabalho de campo etnográfico propicia ao pesquisador o conhecimento direto e experiencial de outras culturas. Para descrever o sistema de significados culturais em seus termos próprios, o etnógrafo realiza uma análise cultural dos dados. Essa análise refere-se a uma investigação sistemática para determinar suas partes e as relações entre as partes e destas com o todo. 0 conhecimento cultural dos informantes é organizado em categorias e todas elas estão relacionadas com a totalidade da cultura ${ }^{3}$.

A análise etnográfica envolve a busca dos elementos constituintes da cultura e de suas relações segundo a conceituação dos informantes ${ }^{3}$. A trajetória conhecida como círculo hermenêutico consiste em um "bordejar dialético contínuo entre a visão da totalidade através das várias partes que a compõem, para uma visão das partes através da totalidade que é a causa de sua existência e vice-versa, buscando fazer com que uma seja a explicação da outra"::105.

Podem-se encontrar estudos a respeito dos significados na área da Enfermagem utilizando a abordagem qualitativa fundamentada em pressupostos teórico-metodológicos do interacionismo simbólico, teoria fundamentada nos dados (Grounded Theory), fenomenologia, etnografia e outras. Os estudos etnográficos na área da Enfermagem buscam interpretar os significados atribuídos pelas pessoas às suas experiências nos processos de saúde e doença ${ }^{4}$ e compreender o cuidado aos seres humanos em diversos contextos sob a ótica de variados atores sociais ${ }^{5}$. Essas investigações trazem contribuições para a atuação dos profissionais, considerando os elementos da cultura de uma determinada realidade, e produzem novos conhecimentos a partir da perspectiva dos atores envolvidos.

As pesquisas etnográficas na área da Enfermagem têm sido realizadas em contextos predominantemente urbanos, considerando a influência da cultura para as práticas de cuidado. A aproximação com outras culturas contribui para 0 direcionamento mais efetivo do cuidado e bem-estar mediante convergência dos saberes científico e popular. 0 êxito do trabalho de campo dependerá da conduta do pesquisador segundo critérios teóricos e metodológicos ${ }^{6}$.

No entanto, são escassos na literatura científica os estudos etnográficos no cenário cultural de instituição de longa permanência para idosos (ILPI) explorando os significados que os idosos atribuem a esta vivência. Define-se ILPI como "instituições governamentais ou não governamentais, de caráter residencial, destinadas ao domicílio coletivo de pessoas com idade igual ou superior a 60 anos, com ou sem suporte familiar, em condição de liberdade, dignidade e cidadania" ":1.

Um estudo realizado com idosos residentes na comunidade mostrou que o ingresso em um asilo para eles significa uma perda simbólica e ameaça a sua identidade. As autoras ressaltam a necessidade de serem consideradas as normas culturais e interpretações dos idosos, bem como suas crenças e preferências no desenvolvimento de ações institucionais ${ }^{8}$. Deste modo, considera-se que os conhecimentos antropológicos conduzem a ações de Enfermagem que valorizam a cultura dos idosos residentes em ILPI.

Este estudo teve como objetivo relatar o desenvolvimento do trabalho de campo etnográfico em uma instituição de longa permanência para idosos.

\section{METODOLOGIA}

Trata-se de relato de experiência do trabalho de campo utilizando o método etnográfico proposto pelos antropólogos Spradley e McCurdy. 0 estudo foi realizado em uma Instituição de Longa Permanência para Idosos (ILPI) de caráter privado com fins lucrativos, em funcionamento regular no município de Curitiba - Paraná, onde residiam 80 pessoas idosas, sendo 60 mulheres e 20 homens. Há três alas na instituição, destinadas aos residentes de acordo com o grau de dependência para as atividades de vida diária e a necessidade de auxilio da equipe de Enfermagem. Na ala residencial estão aqueles considerados independentes, na ala II, os semidependentes, e na ala III, os dependentes.

Neste relato de experiência destacam-se os aspectos metodológicos desta vivência, utilizando ferramentas originárias de estudos culturais antropológicos. A pesquisa etnográfica foi realizada na dissertação apresentada ao curso de Mestrado em Enfermagem, buscando interpretar o significado atribuído pelos idosos à sua vivência na ILPI.

A etnografia é o trabalho de descrever uma cultura, revela o que as pessoas pensam e mostra os significados culturais que utilizam em seu cotidiano ${ }^{1}$. 0 estudo etnográfico constitui etapa inicial da investigação cultural por meio da descrição da cultura de uma comunidade, utilizando técnicas próprias para a obtenção e análise dos dados.

As pessoas aprendem sua cultura fazendo inferências. Para o etnógrafo, as inferências culturais são hipóteses que serão testadas repetidamente para obter relativa certeza de 
que essas pessoas compartilham um sistema particular de significados culturais. As informações a partir das quais o pesquisador realiza inferências são obtidas observando o comportamento cultural, artefatos e as mensagens expressas pelos atores ${ }^{1}$.

As informações foram coletadas por meio da observação participante e da entrevista etnográfica no período de janeiro a agosto de 2010, perfazendo oito meses de trabalho de campo. A coleta e análise das informações seguiram o padrão cíclico do método etnográfico ${ }^{1,3}$, no qual os dados obtidos são repetidamente confirmados e aprofundados por outras observações e entrevistas e o etnógrafo elabora hipóteses que serão testadas com os informantes. Esse processo foi realizado de forma cíclica e contínua no desenvolvimento do trabalho de campo.

0 projeto de pesquisa foi aprovado pelo Comitê de Ética do Setor de Ciências da Saúde em 23 de novembro de 2009 sob parecer $n^{\circ}$. 3657.0.000.091-09. Foram respeitados os preceitos éticos de participação voluntária e consentidos segundo a Resolução 196/96 do Ministério da Saúde. Os critérios de respeito à dignidade do ser humano, proteção, direitos, sigilo e anonimato foram assegurados no Termo de Consentimento Livre e Esclarecido obtido dos possíveis informantes-chave antes do início das entrevistas.

\section{RESULTADO E DISCUSSÃO}

A seguir serão discutidos os caminhos metodológicos adotados desde a entrada no campo, utilização das técnicas da observação participante e entrevista etnográfica, diário de campo, análise das informações e saída do campo.

\section{Entrada no campo}

A entrada no campo ocorreu por meio de facilitadores que contribuíram na realização deste estudo. Inicialmente, foram realizados contatos prévios com pessoas identificadas como middleman, isto é, aquelas que conheciam o local e poderiam intermediar outros contatos e informações sobre o cenário do estudo ${ }^{9}$. Por ocasião da solicitação de autorização para a realização do estudo, foi contatado o diretor da instituição, o qual realizou uma apresentação geral do local.

As enfermeiras e auxiliares de Enfermagem intermediaram minha entrada no campo, por conhecerem há mais tempo o local e os idosos residentes, além de se mostrarem dispostas a fornecer informações. Percebi que, frequentemente, toda a equipe de Enfermagem encontrava-se bastante ocupada em seu trabalho e em certas ocasiões, conversávamos sobre o projeto de pesquisa. Realizei uma reunião com a equipe de Enfermagem para explanar sobre a pesquisa etnográfica que estava realizando e as duas técnicas de coleta de dados: a observação participante e a entrevista com osidosos a serem selecionados.

Em decorrência da entrada no campo, iniciei as observações participantes seguindo as etapas propostas pelo referencial metodológico, da não participação até a participação ativa ${ }^{1}$, no decorrer do trabalho de campo. Nos primeiros dias, coloquei como objetivo a descrição do cenário, buscando observar e registrar as características do local, as pessoas, o que faziam e, por fim, os conhecimentos culturais.

0 contato com os outros atores do cenário foi realizado de forma gradual. Quando informei que estava conhecendo o lar e as pessoas, algumas residentes falavam sobre o local e apresentavam-me às pessoas. Percebi que os idosos possuíam diferentes graus de dependência e busquei conhecê-los em suas características individuais.

\section{Observação participante e entrevista etnográfica}

A observação participante iniciou com observações descritivas para obter um panorama geral da situação, seguindose as focadas e as seletivas, conforme foram delimitados os domínios culturais. Concomitantemente à coleta das informações realizei a análise destas, da qual surgiram novas hipóteses e questões de observação e entrevistas. 0 estudo foi direcionado tendo em vista o objetivo geral de interpretar o significado da vivência dos idosos na instituição. A técnica da observação participante foi útil na descrição do cenário cultural, além da verificação de hipóteses ou afirmações, complementação dos dados, e para a interpretação do que foi dito pelos idosos nas entrevistas.

0 envolvimento nas atividades do cotidiano foi realizado de forma gradual com o propósito de registrar e analisar os dados obtidos. Na observação participante foram observados todos os aspectos da situação, as ações das pessoas e as características físicas. Foram aspectos relevantes para as observações e registros a experiência humana, envolvendo 0 que as pessoas fazem, o que elas falam, o que sabem, o que usam ou constroem (como os artefatos) e onde estão.

Para descrever uma cultura sob o ponto de vista dos nativos, o etnógrafo participa de atividades, faz perguntas, assiste a cerimônias, aprende novas linguagens, faz anotações em diário de campo, observa as cenas culturais e entrevista os informantes-chave ${ }^{3}$. Tive algumas oportunidades de fazer 0 que os idosos faziam, joguei bingo com eles, participei de culto a Deus, fiz ginástica, assisti a filme ou mesmo sentei-me em locais de convivência coletiva para interagir.

Enquanto as observações forneciam informações consistentes sobre o local, senti a necessidade de perguntar aos idosos quanto à percepção deles a respeito da vivência naquele ambiente. Após dois meses do início da coleta dos dados, iniciei as entrevistas formais com os informantes-chave, utilizando um gravador. Então alternava períodos de observação e participação nas atividades e as entrevistas com os idosos.

0 convite para a participação no estudo foi precedido por uma explanação detalhada dos objetivos e procedimentos que envolveram a participação do idoso no estudo. Foram observadas as questões éticas da pesquisa e obtida a assinatura do Termo de Consentimento Livre e Esclarecido. Solicitei a 
permissão para gravar a entrevista etnográfica com os idosos e informei a respeito da confidencialidade das informações.

Os idosos a serem entrevistados formalmente foram selecionados tendo em vista os cinco requisitos para eleger um bom informante: enculturação profunda, envolvimento atual, cena cultural desconhecida, tempo adequado e não analítico. A enculturação é o processo natural de aprender uma cultura particular, e o bom informante é aquele que conhece bastante a respeito da sua cultura. 0 envolvimento atual com as cenas culturais possibilita que o entrevistado lembre em detalhes as atividades ${ }^{3}$.

Muitos dos nossos conhecimentos culturais são tácitos, e, ao estudar uma cena cultural desconhecida, o etnógrafo tende a não ignorar o que é corriqueiro e que faz parte de seu próprio conhecimento cultural. A disponibilidade de tempo livre dos informantes também atua como facilitador ou não no desenvolvimento das entrevistas etnográficas. Além disso, não será um bom informante aquele que analisa a sua própria cultura em uma perspectiva externa ${ }^{3}$.

Os informantes-chave foram selecionados para a entrevista formal etnográfica entre os idosos de ambos os sexos e segundo critérios de inclusão elaborados para identificar aqueles que conheciam bastante a respeito do cotidiano na ILPI, com condição cognitiva de participar da pesquisa avaliada por meio de screening cognitivo ${ }^{10-12}$, disponibilidade de tempo e o desejo de expressar sua vivência na ILPI. Tendo em vista os requisitos para seleção dos informantes-chave, 11 idosos (6 mulheres e 5 homens) participaram das entrevistas formais etnográficas.

A entrevista etnográfica iniciou com questões descritivas de acordo com o roteiro semiestruturado elaborado, seguidas das questões estruturais e, por fim, pelas contrastes. As entrevistas foram realizadas nos quartos dos idosos e também em locais de convivência coletiva da instituição, como a capela e a biblioteca. As entrevistas formais foram aquelas realizadas individualmente e gravadas, enquanto nas entrevistas informais não foi utilizado o gravador e ambas serviram para a compreensão do contexto sociocultural e do ponto de vista dos idosos.

As entrevistas etnográficas formais foram registradas com o auxílio de um gravador, depois da concordância por parte dos informantes, a fim de captar com maiores detalhes as palavras e expressões dos dados emic. Após o término de cada entrevista, a transcrição desses dados gravados foi realizada, utilizando nomes fictícios, por meio de digitação em arquivos do computador utilizando o Microsoft Word, os quais, posteriormente, foram impressos.

\section{0 diário de campo}

Ao longo do trabalho de campo, fui desenvolvendo alguma habilidade na utilização da técnica da observação participante, conciliando as observações, interação com os atores e os registros condensados no momento em que ocorriam as cenas culturais. Nas situações sociais em que participava de forma mais ativa, registrava logo após no diário de campo, buscando relembrar os detalhes observados. De certa forma, essas cenas puderam ser descritas apenas de forma parcial, contendo a minha percepção como mestranda, e segundo o tempo e o espaço em que me localizava, já que muitos eventos ocorriam ao mesmo tempo.

Nos registros etnográficos busquei incluir todas as informações para documentar a situação social em estudo, abrangendo as minhas reações como investigadora, conversas informais, cenas culturais, eventos do cotidiano, entrevistas etnográficas, figuras, documentos, artefatos, entre outros.

Utilizei os quatro tipos de registros etnográficos: condensados, expandidos, o diário de campo e analíticos ou interpretativos ${ }^{1}$. Os registros condensados foram realizados no momento em que ocorriam as cenas culturais, sempre que oportuno ou logo após as mesmas, para não perder a riqueza dos detalhes e tomando-se o cuidado de não sumarizar ou traduzir nas palavras da mestranda.

Os registros expandidos foram utilizados para relembrar os detalhes que não foram possíveis de registrar em tempo real. No diário de campo constaram as experiências, ideias, problemas ou outras percepções que surgiram durante o trabalho de campo. Os registros analíticos e interpretativos expressaram as reflexões, generalizações e interpretações da leitura dos registros anteriores.

\section{Análise etnográfica e saída do campo}

À medida que obtive dados das observações e entrevistas, despendia de tempo para transcrevê-los e analisálos, elaborando novas questões para direcionar o trabalho de campo. Ao mesmo tempo, buscava apoio teórico em outros estudos etnográficos e no aprendizado da metodologia etnográfica para direcionar a minha atuação como "etnógrafa".

A análise etnográfica foi realizada com base nos registros obtidos do trabalho de campo. A primeira etapa para uma busca preliminar de um domínio consistiu em selecionar uma amostra de anotações de uma entrevista etnográfica ou de anotações sobre 0 que as pessoas falaram em uma observação participante. A segunda etapa envolveu a leitura da amostra identificando as relações semânticas e os termos cobertos e incluídos".

Os fenômenos culturais são complexos, pois mesmo uma situação social simples estará imbuída de uma variedade de significados culturais ${ }^{1}$. Procurei limitar o âmbito da investigação mantendo a visão holística. A definição dos domínios culturais a serem investigados em maior profundidade foi realizada mediante identificação daqueles com maior quantidade de informações e tendo em vista o objetivo proposto para o estudo.

Considerando a enorme quantidade de informações obtidas de uma única cena cultural, foi necessário limitar 0 foco do estudo. Foram selecionados alguns domínios para realizar uma análise mais profunda dos significados, limitando 
a abrangência da etnografia. Esse detalhamento dos domínios efetivou-se na análise taxonômica por meio da busca de termos incluídos adicionais.

Ao mesmo tempo em que examina os pequenos detalhes de uma cultura, o etnógrafo procura mapear as características mais amplas do cenário cultural. Além da análise aprofundada dos domínios selecionados, a descrição cultural adequada incluirá um panorama do cenário cultural e as declarações que expressam a visão do todo. Toda cena cultural é mais do que uma mistura de partes, ela consiste em um sistema de significados integrados com base em um padrão maior ${ }^{1}$.

0 tema cultural foi identificado como um princípio recorrente nos domínios, tácito ou explícito, servindo de relação entre os subsistemas do significado cultural. Esse princípio foi expresso em forma de asserção, conectando os domínios e taxonomias e refletindo o significado atribuído pelos idosos à vivência na ILPI.

Ao final do período do trabalho de campo, ganhei muitas amizades dos atores do cenário. Sempre encontrava idosos para conversar e falávamos de assuntos diversos, desde a história de vida deles e, principalmente, o cotidiano deles na instituição. Por vezes ficávamos a tarde toda sentados em um sofá nos fundos do lar, conversando até a hora do jantar deles. Aprendi muito nessas conversas e também nas entrevistas, tanto no que se refere à vivência na ILPI quanto ao cuidado de Enfermagem aos idosos e outros tantos conhecimentos de vida e de mundo.

A saída do campo ocorreu de forma gradual, quando encerrei o trabalho de campo. Desde o início, informava quanto ao período desse trabalho e o mês de término que acabou se estendendo por mais um mês daquele previsto anteriormente. 0 processo cíclico de coleta e análise de dados foi interrompido quando obtive a circularidade das informações e os domínios mais significativos do estudo contiveram informações suficientes para emergir o tema cultural. Após obter a circularidade dos dados, em que muitas informações se repetiam nas entrevistas e tendo em vista a necessidade de partir para uma etapa de discussão dos resultados e elaboração do texto final, foi inevitável concluir a fase de coleta e análise dos dados.

\section{CONSIDERAÇÕES FINAIS}

As vivências no cotidiano da ILPI foram momentos ricos em aprendizado e investigação. Ao finalizar este estudo, aprendi a valorizar ainda mais a dimensão cultural, percebendo a amplitude que ela tem no cotidiano e nos comportamentos humanos. Deste modo, a cultura influencia os modos de viver das pessoas, incluindo suas preferências, sentimentos e os significados que atribuem às suas vivências.

Ao longo do desenvolvimento das etapas do trabalho etnográfico, o cenário cultural - incluindo a estrutura física, os atores e suas relações entre si, as cenas e eventos do cotidiano - foi sendo revelado por meio da observação participante e dos registros etnográficos. Esses dados da realidade e as entrevistas etnográficas com os idosos permitiram conhecer o aparato simbólico, as características institucionais e as expectativas de cuidado, segundo a interpretação dos residentes.

0 aprendizado de uma cultura em sua totalidade não ocorre em apenas um momento, mas de uma forma contínua. Considera-se que esta é uma realidade local e ainda parcialmente apreendida. Mesmo assim, acredita-se que o seu valor está, especialmente, no que foi dito pelos idosos e no vivido neste contexto.

A utilização de um método sistemático para a realização da etnografia favoreceu o direcionamento da atuação no campo, tendo em vista o objetivo que buscava alcançar. Por ser ainda iniciante, a maneira didática apresentada pelos autores facilitou o aprendizado deste método, o qual ocorreu concomitante à sua implementação, na medida em que obtinha informações e as organizava.

As técnicas de coleta e análise de dados etnográficos e o referencial metodológico utilizados mostraram-se valiosos na revelação antropológica. Para a imersão neste universo cultural, contribuíram os conhecimentos teóricos do método etnográfico proposto pelos autores e de outros estudos culturais.

Estamos constantemente aprendendo outras culturas no convívio social de nosso cotidiano, talvez não de forma explícita como no papel de investigadora. No entanto, tendemos a ser, muitas vezes, etnocêntricos, quando a cultura do outro é aprendida em comparação à nossa, que é considerada a mais adequada. Isso porque nossas crenças e valores são construídos em base sólida, ao longo da vida.

Como profissional de saúde, as atitudes etnocêntricas resultam em imposição de cuidado e podem exercer uma influência negativa para o sujeito que busca apoio. Em especial no contexto de uma ILPI, em que o idoso muitas vezes é afastado do seu ambiente de convivência habitual e inserido em atividades institucionais coletivas, possivelmente levam a angústias, tensões psicológicas e suas consequências deletérias na autoestima, autonomia e liberdade das pessoas idosas.

Entendo que o olhar antropológico é parte do aparato instrumental utilizado pelo enfermeiro em sua prática. Para desenvolver esta habilidade, o profissional faz uso de conhecimentos transculturais e de técnicas sistematizadas, como da observação participante e da entrevista etnográfica.

0 desenvolvimento da habilidade do olhar antropológico entre os profissionais de saúde, em especial os de Enfermagem, pela proximidade que desenvolvem com os seres humanos que cuidam, pode aperfeiçoar as práticas de saúde. Ao mesmo tempo, o despertar para o cuidado enquanto essência do humano contribui para as reflexões no intuito de compreender a complexidade deste fenômeno.

Outras pesquisas etnográficas fornecerão novas perspectivas a respeito das práticas da Enfermagem em 
populações específicas. Ao mesmo tempo, a divulgação desses estudos possibilita o intercâmbio de informações, proporcionando o crescimento como profissão, ciência e arte e, consequentemente, o maior reconhecimento da relevância social.

\section{REFERÊNCIAS}

1.Spradley JP. Participant observation. Orlando: Holt, Rinehart and Winston; 1980.

2.Geertz C. 0 saber local. 2. ed. Petrópolis: Vozes; 1999.

3.Spradley JP, McCurdy DW. The ethnographic interview. New York(USA): Holt, Rinehart and Winston; 1979.

4.Lenardt MH. A hospitalização desnudando o microcosmo de uma unidade hospitalar [tese]. Florianópolis(SC): Centro de Ciências da Saúde, Universidade Federal de Santa Catarina; 2001.

5.Santos SMA. 0 cuidador familiar de idosos com demências: um estudo qualitativo em famílias de origem nipo-brasileiras e brasileiras [tese]. Campinas (SP): Faculdade de Educação, Universidade Estadual de Campinas; 2003.

6.Sousa LB, Barroso MGT. Pesquisa etnográfica: evolução e contribuição para a Enfermagem. Esc. Anna Nery Rev. Enferm. 2008 mar; 12(1): 150-5.

7. Ministério da Saúde (Brasil), Agência Nacional de Vigilância Sanitária. Resolução da Diretoria Colegiada - RDC n 283 de 26 de setembro de 2005. Brasília (DF): Diário Oficial da União; 26 set 2005: Seção 1: 1.

8. Silva LR, Vásquez-Garnica EK. El cuidado a los ancianos: las valoraciones en torno al cuidado no familiar. Texto \& contexto enferm. 2008 jun; 17(2): 225-31.

9.Spradley JP, McCurdy DW. The cultural experience: ethnography in complex society. USA: Science Research Associates; 1972.

10.Folstein MF, Folstein SE, Mchugh PR. Mini-mental state: a practical method for grading the cognitive status of patients for the clinician. J Psychiatr Res. 1975 nov.; 12(3): 189-98.

11.Brucki SMD, Nitrini R, Caramelli P, Bertolucci PHF, Okamoto IH. Sugestões para o uso do miniexame do estado mental no Brasil. Arq. Neuro-Psiquiatr. 2003; 61(3B): 777-81.

12. Bertolucci PHF, Brucki SMD, Campacci SR, Juliano Y. 0 miniexame do estado mental em uma população geral. Impacto da escolaridade. Arq. Neuro-Psiquiatr. 1994 mar; 52(1): 1-7.

\section{NOTA}

aArtigo extraído da Dissertação do Curso de Mestrado em Enfermagem do Programa de Pós-Graduação em Enfermagem da Universidade Federal do Paraná (UFPR): "A vivência em uma instituição de longa permanência: significados atribuídos pelos idosos". 